\title{
The importance of the PD-1/PD-L1 pathway at the maternal-fetal interface
}

Matyas Meggyes ${ }^{1,2^{*}}$ (D), Eva Miko ${ }^{1,2}$, Brigitta Szigeti ${ }^{1}$, Nelli Farkas ${ }^{3}$ and Laszlo Szereday ${ }^{1,2}$

\begin{abstract}
Background: Our goal with this study was to investigate the contribution of PD-1/PD-L1 immune-checkpoint pathway to maternal immunotolerance mechanisms.

Methods: Thirteen healthy pregnant women and 10 non-pregnant controls were involved in this project. PBMCs and DICs were isolated from peripheral blood and from decidual tissues. After the characterization of different immune cell subsets, we used fluorochrome-conjugated monoclonal antibodies to measure the expression level of PD-1, PD-L1, NKG2D, and CD107a molecules by flow cytometry.

Results: We measured significant alternations in the proportion of decidual immune cell subsets compared to the periphery. Elevated PD-1 expression by decidual CD8+ T, CD4+ T, and NKT-like cells were also detected accompanied by the increased PD-L1 expression by decidual CD4+ T, Treg, NKT-like and CD56 + NK cell subsets compared to peripheral blood. The cytotoxic potential was significantly higher in PD-1- decidual immune cells compared to the periphery, however we measured a significantly lower cytotoxicity in the decidual PD-1+ CD8+ T cells compared with the peripheral subsets. An activation receptor NKG2D expression was decreased by the PD-1+ CD8+ T subsets in the first trimester compared to non-pregnant condition but the expression level of the decidual counterparts was significantly elevated compared to the periphery. The cytotoxic potential of decidual PD1/NKG2D double positive CD8+ T cells was significantly decreased compared to the peripheral subsets.
\end{abstract}

Conclusions: Based on our results we assume that PD-1/PD-L1 pathway might have a novel role in the maintaining of the local immunological environment. Accompanied by NKG2D activating receptor this checkpoint interaction could regulate decidual CD8 Tc cell subsets and may contribute maternal immunotolerance.

Keywords: Pregnancy, Maternal-fetal interface, PD-1, PD-L1, Maternal immunotolerance

\section{Background}

Pregnancy is a useful model to investigate natural immunotolerance since the semi-allogeneic fetus will neither be attacked nor rejected by the maternal immune system, but rather successfully accepted by the mother. A healthy pregnancy requires that the maternal immune system recognizes the antigens from paternal origin expressed by the fetus thereby developing maternal immunotolerance against the fetus. A failure in the mechanism of recognition consequently the impaired maternal immune tolerance may result in abnormal

\footnotetext{
* Correspondence: meggyes.matyas@pte.hu

'Department of Medical Microbiology and Immunology, University of Pecs,

Medical School, 7624 Pecs, 12 Szigeti Street, Pecs, Hungary

${ }^{2} J a n o s$ Szentagothai Research Centre, 7624 Pecs, 20 Ifjusag Street, Pecs,

Hungary

Full list of author information is available at the end of the article
}

pregnancies, such as recurrent spontaneous abortion or preeclampsia. For many years, immunotolerance during pregnancy was described as a Th2-type immune response [1]. An altered cytokine production toward Th2-type cytokines during pregnancy is part of these immunological changes and promotes maternal-fetal tolerance (MFI) [2]. Furthermore, the elevated ratio of natural killer $(\mathrm{CD} 56+\mathrm{NK})$ and NKT-like cells at the MFI suggests an important role of both the innate and the adaptive immune system [3].

The transmembrane protein Programmed cell death protein 1 (PD-1) is a member of the B7-CD28 family [4]. As a co-inhibitory molecule PD-1 is expressed by a variety of activated immune cells, including $\mathrm{T}(\mathrm{CD} 4+$, CD8+, NKT-like and regulatory $\mathrm{T}$ (Treg)) cells, B cells, monocytes and dendritic cells $[5,6]$. After activation, the

(c) The Author(s). 2019 Open Access This article is distributed under the terms of the Creative Commons Attribution 4.0 International License (http://creativecommons.org/licenses/by/4.0/), which permits unrestricted use, distribution, and reproduction in any medium, provided you give appropriate credit to the original author(s) and the source, provide a link to the Creative Commons license, and indicate if changes were made. The Creative Commons Public Domain Dedication waiver (http://creativecommons.org/publicdomain/zero/1.0/) applies to the data made available in this article, unless otherwise stated. 
receptor expression could be rapidly up-regulated within $24 \mathrm{~h}$ by naive $\mathrm{T}$ cells [7]. The receptor has been originally identified on exhausted $\mathrm{T}$ cells, and in most cases the blockade of PD-1 signaling has been shown to revert the dysfunctional state of exhausted CD8+ T cells $[8,9]$.

Programmed cell death ligand-1 and ligand-2 (PD-L1 and PD-L2) are members of the B7-CD28 family being the two known ligands for PD-1 [6]. The two PD-1 ligands have different expression patterns, while PD-L1 is expressed in many tissue types, including the heart, spleen, and antigen-presenting cells [10], the expression of PD-L2 is very limited predominantly restricted to macrophages and dendritic cells [11, 12]. However Nagamatsu et al. have shown that decidual stromal cells express both PD-1 ligands in term pregnancy [13]. PD-L1 expression by non-hematopoietic cells [14, 15] and in high levels by tumor tissues and different lymphoma subtypes have also been reported [16].

After binding to its ligands, PD-1 can inhibit autoreactive $\mathrm{T}, \mathrm{B}$ and effector $\mathrm{T}$ cells to induce $\mathrm{T}$ cell tolerance and regulate local inflammation [17]. PD-1 regulates $\mathrm{T}$ cell homeostasis, it also has an important role in peripheral tolerance and in the prevention of autoimmunity $[18,19]$. However, the overexpression of PD-1 can cause $\mathrm{T}$ cell dysfunction and exhaustion accompanied by impaired IFN- $\gamma$ secretion [20]. Therefore this pathway has a significant role in the balance between effective immunity and self-tolerance. Similarly to TIM-3 mediated regulation [21], PD-1 signaling in CD8 + $\mathrm{T}$ cells is characterized by the diminish of effector functions [22] and this could play a role in the complex mechanism of peripheral immune tolerance [23].

A growing body of evidence proved the significance of PD-1 and their ligands in a different type of cancers [24-26], and emphasize the therapeutic potential of this pathway in the treatment of patients with progressive metastatic non-small cell lung cancer (NSCLC) [27]. The importance of the PD-1/PD-L1 pathway in transplantation models and autoimmunity was also extensively investigated. Many papers reported that disruption of PD-L1 contributes to graft destruction by the host $[28,29]$, furthermore the deficiency of PD-1 enhances $T$ cell proliferation and graft rejection [29, 30]. The absence of PD-L1 and PD-L2 facilitates the accumulation of activated lymphocytes and the development of $\mathrm{T}$ cell-mediated autoimmunity [12].

NKG2D is an activating receptor expressed by NK and NKT-like cells, but it is also present on CD8+ T cells. After binding to its ligands such as UL16 binding protein 1 (ULBP1), ULBP2, ULBP3, major histocompatibility complex class related molecules A and B (MICA, MICB) it has a costimulatory function and contribute to the cytotoxic activity of these effector cells [31]. Although MICA expression restricted to gastric and glandular epithelial cells, the expression pattern of ULBP appears to be extensive in healthy adult tissues since ULBP transcripts were observed in kidney, prostate, uterus, tonsil, lymph node tissues [32] and trophoblast cells [33]. Currently one of the most efficient immunotherapy is to block the PD/PD-L1 checkpoint inhibitor pathway $[34,35]$. A recent study reported a connection between a higher PD-L1 and lower NKG2D ligand expression in a radioresistant cell [36]. Therefore it might be interesting to investigate the co-expression of PD-1 and NKG2D receptors by CD8+ $\mathrm{T}$ and NKT-like cells since NK cells do not express PD-1 receptor.

Based on the above-mentioned studies from different aspects, PD-1 and its ligands have a critical role to evolve and maintain peripheral immune tolerance [37], nevertheless much less study has been published in the context of the immunoregulation of PD-1 and its ligands during healthy human pregnancy. An interesting study has been reported that in allogeneic pregnancy a quantitative expansion of alloreactive $\mathrm{T}$ cells in parallel with reduced Treg function by blocking the surface PD-L1 resulted in decreased fetal survival. It seems that the PD-L1 promote fetal survival by maintaining adequate Treg function. [38]. This paper draws the attention to the importance of PD-1 in normal pregnancy since the expression of PD-L1 by villous syncytiotrophoblasts and cytotrophoblasts could induce the exhaustion of the PD-1 positive lymphocytes [38].

Investigation of the immune-checkpoint molecules at the MFI is crucial in order to clarify the exact immunological relationship between the mother and the fetus. This knowledge accompanied by epigenetic examinations [39] could help us to understand the background of pathological pregnancy conditions such as preeclampsia and intrauterine growth restriction. One of the biggest challenges in reproductive immunology is to find a proper biomarker or biomarker panel for early diagnosis of preeclampsia. We hope that our results supplemented with previous findings $[40,41]$ will contribute to understanding the background of this pathological condition.

The aim of this present study was to clarify the contribution of PD-1/PD-L1 immune-checkpoint pathway in the induction of maternal tolerance during healthy pregnancy.

\section{Methods}

\section{Participants}

To investigate the PD-1/PD-L1 pathway 13 healthy women who underwent pregnancy termination for non-medical reasons in the first trimester of their pregnancy were recruited. Our control group was formed by 10 healthy non-pregnant women. None of the women had any significant medical history, current or recent 
illnesses, or were taking medications. All subjects affected by any kind of pregnancy-related complication and/or infection, alcohol abuse, pre-pregnancy disease, AIDS, in vitro fertilization pregnancies, diabetes mellitus, renal diseases, immune-associated disease and deep vein thrombosis were excluded.

\section{Lymphocyte separation, cryopreservation, thawing}

Peripheral blood mononuclear cells (PBMC) were isolated from heparinized venous blood using Ficoll-Paque density gradient (GE Healthcare, UK). Separated cells were then washed twice in RPMI 1640 medium (Lonza, Switzerland), counted, centrifuged and resuspended in human serum containing 10\% DMSO (Sigma-Aldrich, USA) for cryoprotection. Subsequently, the cells were aliquoted in cryovials and stored in a $-80{ }^{\circ} \mathrm{C}$ mechanical freezer. Thawing was carried out on the day of fluorescent cell labeling as quickly as possible in a $37^{\circ} \mathrm{C}$ water bath and DMSO was washed out twice in RPMI 1640 medium.

\section{Isolation of decidual immune cells (DICs)}

DIC were obtained from the decidual tissue from clinically normal women after pregnancy termination in the first trimester. Isolation of DICs from decidual tissue was performed as previously described [42]. Briefly, the deciduas were aseptically isolated from fetal tissues and the chorionic villi under a dissecting microscope. Subsequently, the separated tissue bits were cut into pieces and digested in RPMI 1640 supplemented with $0.5 \%$ collagenase type IV (Sigma-Aldrich, USA) at $37^{\circ} \mathrm{C}$ for $60 \mathrm{~min}$ with gentle stirring on a magnetic stirrer. Following the digestion procedure, the cell suspension was passed through a $100 \mu \mathrm{m}$ cell strainer with a syringe plunger (Becton Dickinson, USA) to prepare a single cell suspension. Next, for tissue debris elimination the samples were washed in RPMI 1640 supplemented with penicillin and streptomycin $(\mathrm{P}+\mathrm{S})$ (Lonza, Switzerland) at $1200 \mathrm{rpm}$ for $10 \mathrm{~min}$. The supernatant was aspirated and the pellet was resuspended and passed through a $70 \mu \mathrm{m}$ cell strainer (Becton Dickinson, USA). After another centrifugation at $1200 \mathrm{rpm}$ for $10 \mathrm{~min}$, the pellet was resuspended and overlaid on a Ficoll-Paque gradient and centrifuged at $2000 \mathrm{rpm}$ for $20 \mathrm{~min}$. DICs were collected, washed, filtered via a $40 \mu \mathrm{m}$ cell strainer (Becton Dickinson, USA) and resuspended in RPMI 1640 medium containing 10\% fetal bovine serum (Gibco, USA), penicillin and streptomycin. Cryoprotection and thawing procedures were performed as previously described.

\section{Antibodies}

For surface and intracellular staining, freshly thawed PBMC and DICs were used. The following monoclonal antibodies were used: fluorescein isothiocyanate (FITC)-conjugated anti-human CD4 (BD Biosciences, USA), FITC-conjugated anti-human CD107a (BD Biosciences, USA), phycoerythrin (PE)-conjugated anti-human PD-1 (Beckmann-Coulter, USA), PE/Cy7-conjugated anti-human NKG2D (BD Biosciences, USA), allophycocyanin (APC)-conjugated antihuman CD56 (BD Biosciences, USA), APC-conjugated anti-human FoxP3 (eBioscience, USA), APC/H7-conjugated anti-human CD8 (BD Biosciences, USA), Brilliant Violet (BV421)-conjugated anti-human PD-L1 (BD Biosciences, USA), BV510-conjugated anti-human CD3 (BD Biosciences, USA).

\section{Intracellular staining}

FoxP3 Staining Buffer Set (eBioscience, USA) was used according to the manufacturer's instructions to identify the Treg population. Briefly, cells were permeabilized in $1 \mathrm{ml}$ fixation/permeabilization buffer (Concentrate/ Diluent $1: 4$ ) for $1 \mathrm{~h}$ at $4{ }^{\circ} \mathrm{C}$ for in the dark. Next, the samples were washed twice in the buffer and stained with the APC-conjugated anti-human FoxP3 monoclonal antibody for $1 \mathrm{~h}$ at $4{ }^{\circ} \mathrm{C}$ in the dark. The cells were washed twice in the buffer, fixed with $1 \%$ PFA and stored at $4{ }^{\circ} \mathrm{C}$ in complete darkness until FACS analysis.

\section{Flow cytometry}

Cell-surface expression of specific markers was measured in different immune populations using fluorochrome-conjugated monoclonal antibodies. $10^{6}$ cell in $100 \mu \mathrm{l}$ phosphate-buffered saline (PBS)/tube was incubated for $30 \mathrm{~min}$ at room temperature with the fluorochrome-labeled monoclonal antibodies according to the manufacturer's protocol. After a washing step with PBS, the cells were fixed in $300 \mu \mathrm{l} \mathrm{PBS}$ containing 1\% paraformaldehyde (PFA) and stored at $4{ }^{\circ} \mathrm{C}$ in complete darkness until FACS analysis. Flow cytometer settings were checked using Cytometer Setup and Tracking beads (BD Biosciences, USA) according to the manufacturer's protocol. To determine compensation values, spectral overlap values are measured for all fluorophores, via single-color controls. Data acquisition and analyses were performed by FACS Canto II flow cytometer (BD Biosciences, USA) equipped with the FACSDIVA V6. software (BD Biosciences, USA).

\section{CD107a degranulation assay}

CD107a surface marker expression was measured by flow cytometry to evaluate the cytotoxic activity of CD8+ T cells. PBMC were incubated in the presence of FITC-conjugated anti-human CD107a monoclonal antibody in RPMI 1640 medium containing $10 \%$ fetal bovine serum, $\mathrm{P}+\mathrm{S}$, ionomycin (Sigma-Aldrich, USA) and phorbol myristate acetate (Sigma-Aldrich, USA) for $4 \mathrm{~h}$ at $37^{\circ} \mathrm{C}$ in an atmosphere containing $5 \% \mathrm{CO}_{2}$. Following the stimulation, cells were washed and resuspended in PBS then incubated with BV510-conjugated anti-human CD3, APC-H7-conjugated 
anti-human CD8 together with PE-conjugated anti-human PD-1 and PE/Cy7-conjugated anti-human NKG2D antibody for $30 \mathrm{~min}$ at room temperature. After the staining, the cells were washed in PBS, fixed with 1\% PFA and stored at $4{ }^{\circ} \mathrm{C}$ in complete darkness until FACS analysis.

\section{Statistical analysis}

Statistical significance was determined using paired and unpaired sample t-test with statistical software SPSS version 23 package. Normality of our data was tested by Shapiro-Wilk test. A normal distribution was confirmed. Since we didn't have endometrial tissues from non-pregnant women, statistical comparison was performed using unpaired sample t-test only between PBMC from both groups and never between DIC and PBMC from the non-pregnant group. Data obtained from the same healthy pregnant individuals investigating DIC and PBMC were analysed using paired sample t-test. Differences were considered significant if the $p$ value was equal to or less than 0.05 .

\section{Results}

Phenotypic analyses of peripheral and decidual immune cell populations in 1st-trimester healthy pregnant women and peripheral immune cell populations in non-pregnant women

In our phenotypic examination, different immune cell populations from peripheral blood and from the decidual tissue were compared (Fig. 1). Firstly, we observed a significant elevation in the ratio of the decidual CD8+ T cell subpopulation in parallel with a significant decrease in the ratio of decidual $\mathrm{CD} 4+\mathrm{T}$ cell subpopulation within CD3+ cell population compared to the peripheral counterparts (Table 1). The percentage of the decidual Treg subpopulation were slightly increased compared to the periphery, but it did not reach a significant level. Similarly to our findings many papers previously reported that the ratio of decidual CD56 + NK cells and CD56 ${ }^{\text {dim }} \mathrm{NK}$ and CD56 ${ }^{\text {bright }} \mathrm{NK}$ cell subsets were significantly elevated compared to the periphery (Table 1). The percentage of the NKT-like cells did not change significantly between the investigated groups (Table 1).

The percentage of peripheral immune cell populations did not show any significant difference between women from the 1st-trimester and non-pregnant women.

We further analyzed the percentage of $\mathrm{CD} 8+\mathrm{T}$ and $\mathrm{CD} 4$ $+\mathrm{T}$ cells in the PD-1+CD3+ T cell population. The percentage of CD8+ T cells among the PD- $1+\mathrm{CD} 3+\mathrm{T}$ cell population was significantly elevated in decidua of 1st-trimester women and in the periphery of non-pregnant women compared to the periphery of 1st-trimester pregnant women. The percentage of CD4+ T cells among the PD-1+CD3+ T cell population was significantly reduced in decidua of the 1st-trimester compared to the peripheral counterpart of the 1st-trimester (Table 1).

\section{PD-1 and PD-L1 expression by peripheral and decidual immune cell populations in 1st-trimester healthy} pregnant women and peripheral immune cell populations in non-pregnant women

Surface expression of PD- 1 by CD8+ T, CD4+ T, and NKT-like cells was measured by flow cytometry. The receptor expression was significantly increased in all investigated decidual immune cell subpopulations compared to the peripheral counterparts (Fig. 2). PD-1 expression by peripheral $\mathrm{CD} 8+\mathrm{T}$ and $\mathrm{CD} 4+\mathrm{T}$ cells were significantly decreased in the first trimester compared to the non-pregnant condition (Fig. 2a and b).

The expression level of PD-L1 shows a unified pattern. The expression of the PD-1 ligand was significantly elevated by all decidual immune cell populations compared to the periphery (Fig. 3.). In the case of the Treg subpopulation, we further detected a significantly increased PD-L1 expression in the 1st-trimester of pregnancy compared to the non-pregnant group (Fig. 3b).

Cytotoxic activity of PD-1 receptor positive and negative peripheral and decidual immune cell populations in 1sttrimester healthy pregnant women and peripheral immune cell populations in non-pregnant women To define the cytotoxic potential, CD107a degranulation assay was used. CD107a expression by the PD-1+ cell populations did not show any significant differences between the investigated groups (Fig. 4a). In contrast, decidual PD-1 negative immune cells showed significantly elevated cytotoxicity compared to the peripheral counterpart (Fig. 4b).

Next, we determined the cytotoxic potential of the CD8+ T cells depending on the presence of the PD-1 receptor. Significantly decreased CD107a expression by the decidual PD-1+CD8+ T cell subset was revealed compared to the peripheral counterparts (Fig. 4c). However, this higher value was significantly lower compared to the non-pregnant control group (Fig. 4c). Notable differences in the cytotoxicity by the PD-1 negative CD8+ $\mathrm{T}$ cell populations have not been detected between the examined groups (Fig. 4d).

\section{Co-expression of NKG2D activating receptor and PD-1} inhibitory immune-checkpoint receptor by CD8+ T cells in peripheral and decidual immune cell populations in the 1st-trimester healthy pregnant women and peripheral immune cell populations in non-pregnant women NKG2D receptor expression by the CD8+ T cells was measured, and we detected a significant elevation in the 1st-trimester healthy pregnant women compared to the non-pregnant group (Fig. 5a). As shown in Fig. 5b, 


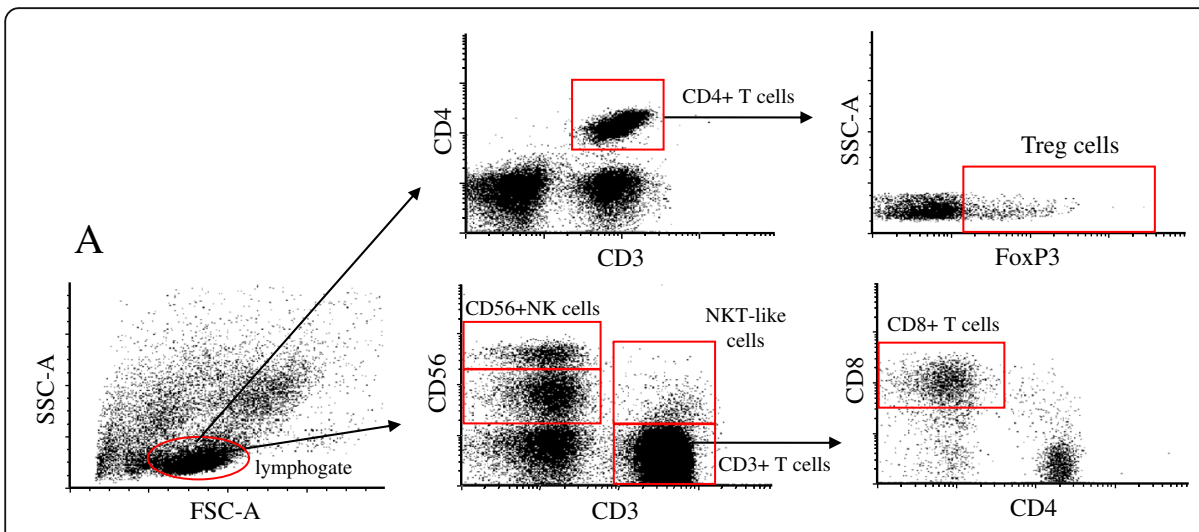

B
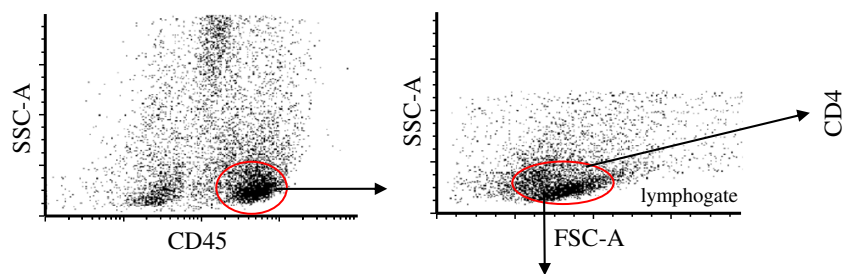

lymphogate

CD45

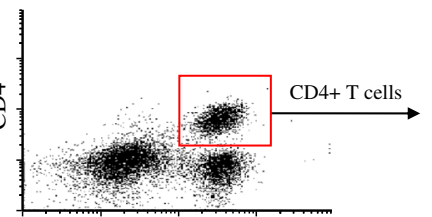

CD3

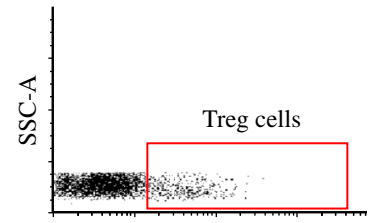

FoxP3

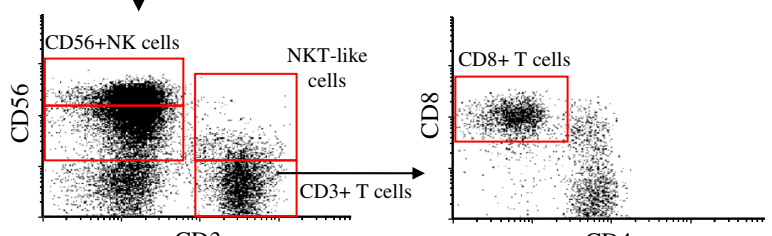

CD3

CD4

Fig. 1 Flow cytometry gating strategy for peripheral and decidual immune cell subpopulations a, Lymphocytes from peripheral blood were gated on FSC-A versus SSC-A. Cell surface antibodies were used to identify, CD8+ T, CD4+ T, Treg cells, CD56 + NK, and NKT-like cell subpopulations. b Immune cells from decidual tissues were gated using side-scatter area (SSC-A) and CD45 gate. Decidual lymphocytes were selected from CD45+ cells on the basis of forward-scatter area (FSC-A) and SSC-A. Cell surface antibodies were used to identify CD8+ T, CD4+ T, Treg cells, CD56 + NK, and NKT-like cell subpopulations

Table 1 Phenotype analysis of different immune cell population in healthy pregnant and in non-pregnant women

\begin{tabular}{|c|c|c|c|c|}
\hline & Non-pregnant PBMC & $1^{\text {st }}$-trimester PBMC & $1^{\text {st }}$-trimester DIC & $p$-value \\
\hline CD8+ T cells in CD3+ cells & $33.21 \pm 7.27$ & $34.00 \pm 6.90$ & $56.60 \pm 15.07^{*}$ & $*<0.01$ \\
\hline CD4+ T cells in CD3+ cells & $57.28 \pm 10.10$ & $52.51 \pm 8.96$ & $31.02 \pm 16.70^{*}$ & ${ }^{*}<0.01$ \\
\hline Treg cells & $2.19 \pm 0.77$ & $1.71 \pm 0.79$ & $2.95 \pm 3.44$ & NS \\
\hline CD56+NK cells & $18.44 \pm 5.61$ & $13.61 \pm 5.17$ & $48.45 \pm 22.36^{*}$ & $*<0.01$ \\
\hline CD56 $6^{\operatorname{dim}} \mathrm{NK}$ cells & $16.43 \pm 5.23$ & $11.99 \pm 4,28$ & $27.30 \pm 14.14^{*}$ & ${ }^{*}<0.01$ \\
\hline CD56 bright NK cells & $2.04 \pm 1.12$ & $1.42 \pm 1.03$ & $21.17 \pm 12.93^{*}$ & $*<0.01$ \\
\hline NKT-like cells & $3.55 \pm 3.37$ & $3.74 \pm 2.15$ & $4.46 \pm 3.67$ & NS \\
\hline CD8+ T cells in PD- $1+$ CD3+ cells & $41.59 \pm 10.23^{* *}$ & $31.48 \pm 9.09$ & $62.52 \pm 15.19^{*}$ & $\begin{array}{l}*<0.01 \\
{ }^{*}<0.03\end{array}$ \\
\hline CD4+ T cells in PD- $1+$ CD3+ cells & $45.06 \pm 13.11$ & $47.39 \pm 15.24$ & $28.06 \pm 15.30^{*}$ & ${ }^{*}<0.02$ \\
\hline
\end{tabular}

Statistical comparisons were made by Student's t-test between non-regnant PBMC vs. $1^{\text {st }}$-trimester PBMC group and $1^{\text {st }}$-trimester PBMC vs. $1^{\text {st }}$-trimester DIC group. The results were expressed as the mean value \pm standard deviation (SD). Differences were considered significant when the value of $p$ was equal to or less than 0.05. Non-significant (NS)

*significantly differ from $1^{\text {st }}$ trimester PBMC, ** significantly differ from $1^{\text {st }}$ trimester PBMC 


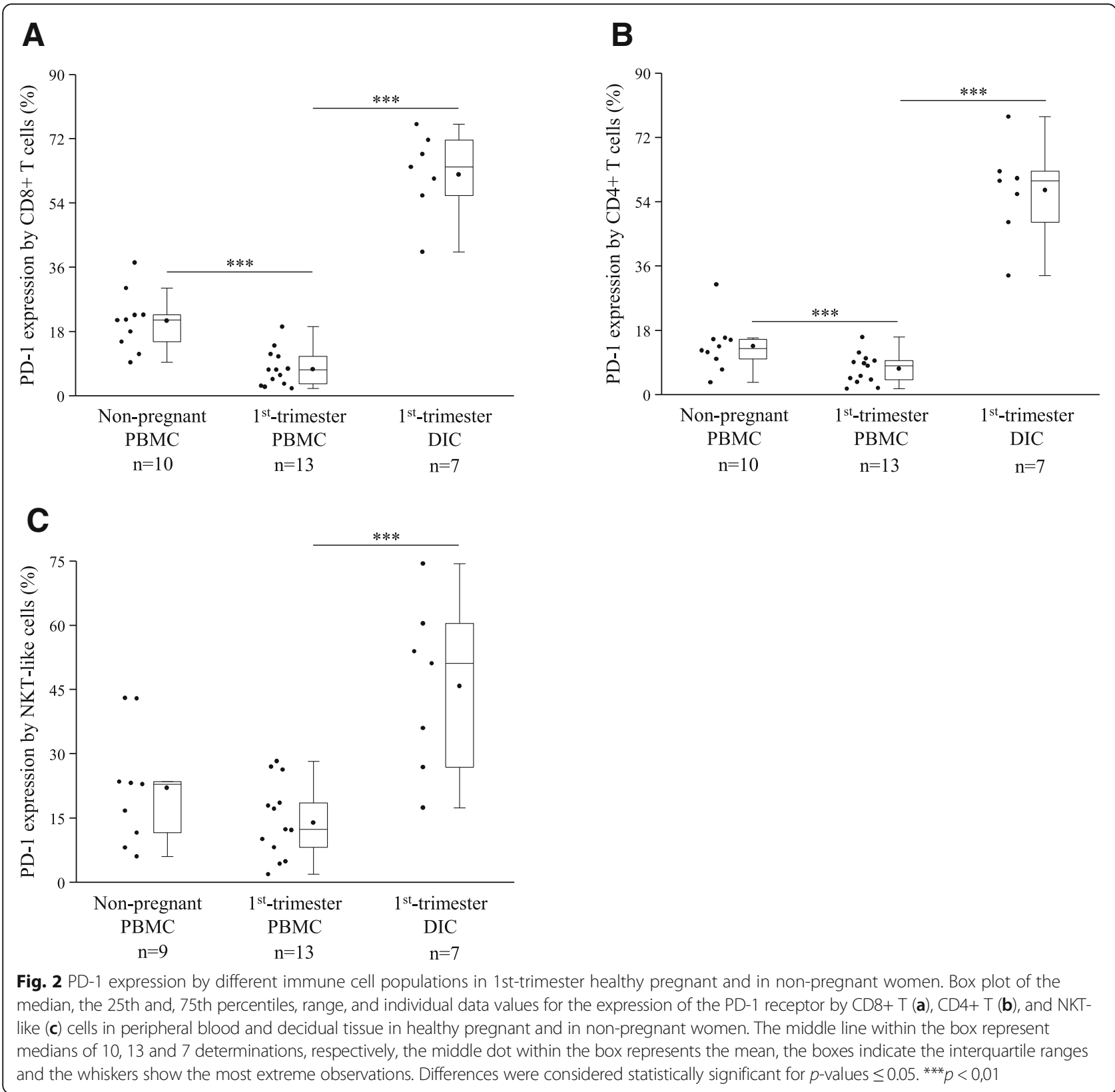

significantly higher NKG2D expression by the decidual PD-1+ CD8 + T cells was observed compared the peripheral PD-1+ CD8 + T cells. Our further analyses detected a significantly decreased NKG2D expression by PD-1+ CD8+ T cells from the periphery in 1st-trimester healthy pregnant women compared to non-pregnant controls (Fig. 5b).

We also measured the cytotoxic potential of the NKG2D/PD-1 double positive CD8+ T cells, and we detected a significantly reduced CD107a expression by the decidual subpopulation compared to the peripheral counterpart (Fig. 5c).

\section{Discussion}

During a healthy pregnancy, the maternal immune system undergoes significant changes in order to tolerate the presence and ensure the proper environment for the fetus. Besides controlling fetal development, the maternal immune system has to react to infections and act against tumor cells. Therefore, abnormalities in this sensitive immunological balance could lead to serious consequences in fetal development including recurrent spontaneous abortion, intrauterine grow restriction or early-onset preeclampsia.

The precise mechanism of this natural immunotolerance against the fetus is still not fully elucidated and 


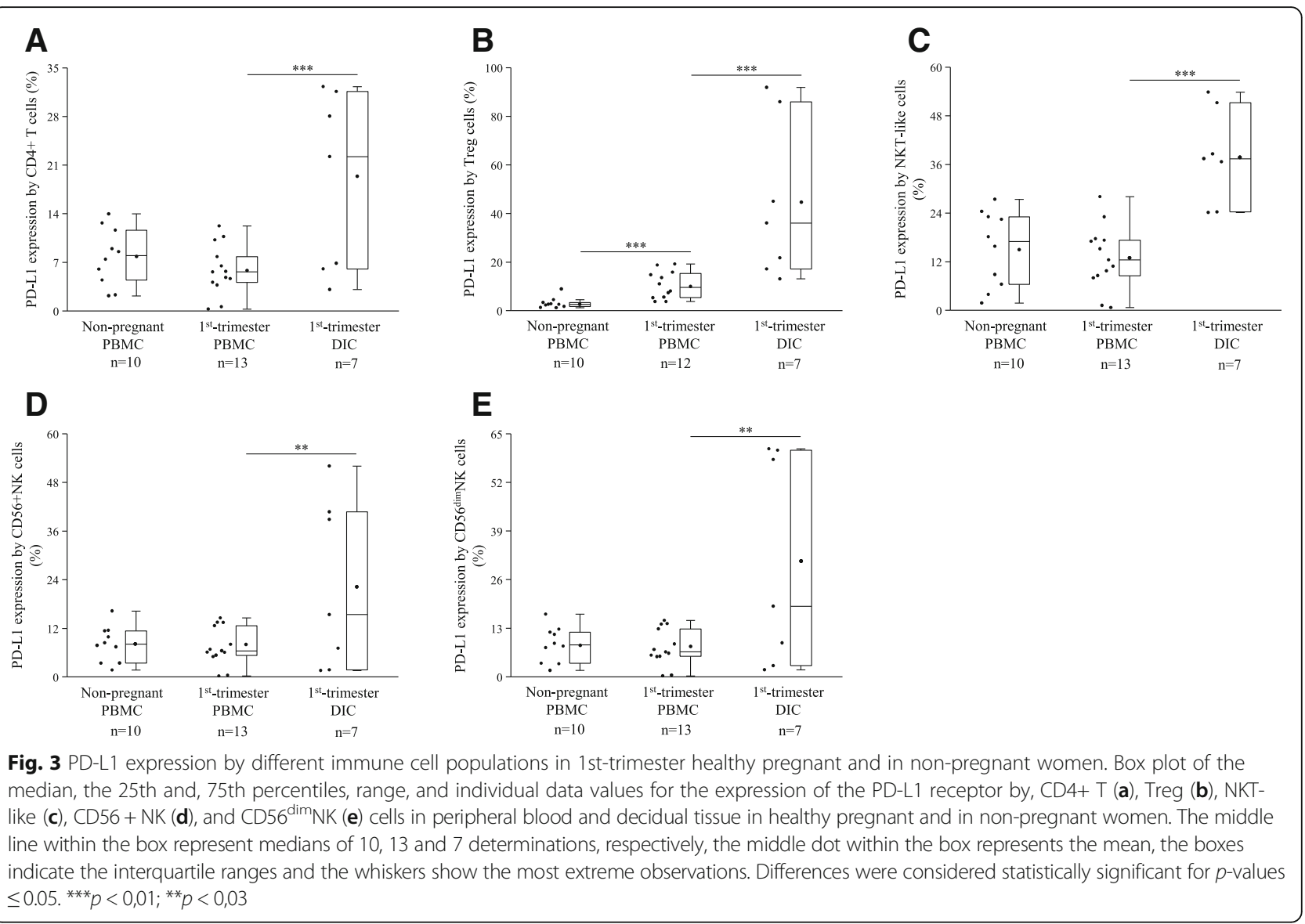

exploring the background of these contradictory immune functions could help us to understand the maternal immune homeostasis. Immunoregulation has been realized by the balance of activating and inhibitory immune responses. Checkpoint inhibitors (PD-1, TIM-3, TIGIT, etc.) are one of the key players in the regulation of effector immune responses and cellular interactions preventing from deleterious autoimmune effects, but their significance in maternal-fetal relation is still scarce. The goal of this present study was to evaluate the contribution of the PD-1/PD-L1 immune-checkpoint pathway to maternal immunotolerance during a healthy pregnancy.

To determine the relevance of PD-1 and PD-L1 in pregnancy, firstly we identified several decidual and peripheral immune cell populations, including $\mathrm{T}$ - and CD56 + NK cell subsets in the first trimester of pregnancy. There are significant differences in the proportion of the decidual immune cell subsets compared to the periphery. Our phenotypic analyses confirmed that during pregnancy the percentage of decidual $\mathrm{CD} 8+\mathrm{T}$-, CD56 + NK-, CD56 ${ }^{\mathrm{dim}} \mathrm{NK}$, and CD56 ${ }^{\text {bright }} \mathrm{NK}$ cells were significantly increased compared to the peripheral blood accompanied by a significantly decreased percentage of CD4+ T cells.
There are few publications investigating the presence of PD-1 receptor expressed by immune cells at the human MFI [43, 44]. Taglauer et al. observed an increased presence of PD-1+ CD3+ T cells in the first-trimester decidua compared to the endometrium in non-pregnant controls [44]. Another paper demonstrated an elevated PD-1 expression by the decidual CD8+ T- and CD4+ T cell subpopulation compared to the peripheral counterparts in the first trimester of pregnancy [45]. Consistent with this finding we found that the percentage of decidual CD8+ T cells among in PD- $1+$ CD3+ T cells was significantly increased compared to the periphery along with the decreased percentage of decidual CD4+ T cells among in PD-1+ CD3 T cells [44]. In line with this result, we further revealed that the percentage of PD-1+CD8+ T cells significantly decreased in the periphery from the first-trimester of pregnancy compared to the non-pregnant group. One possible purpose for the accumulation of PD-1+CD8+ T cells at the MFI could be the recruitment of cytotoxic $\mathrm{T}$ cells with an anti-microbial effect. At the same time, these cells are under strict control via a PD-1/PD-L1 pathway preventing harmful inflammatory effects.

We also investigated the PD-1 expression by different decidual $\mathrm{T}$ cell subsets from the first trimester of 
A

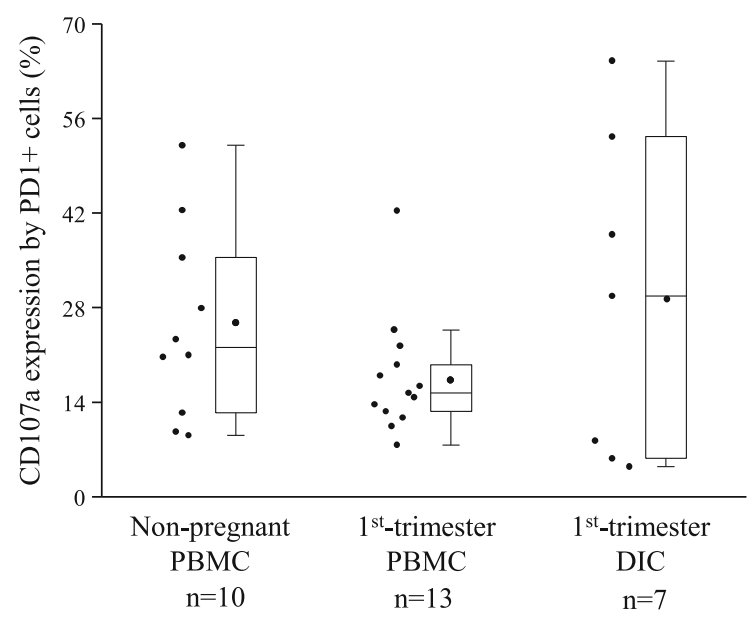

C

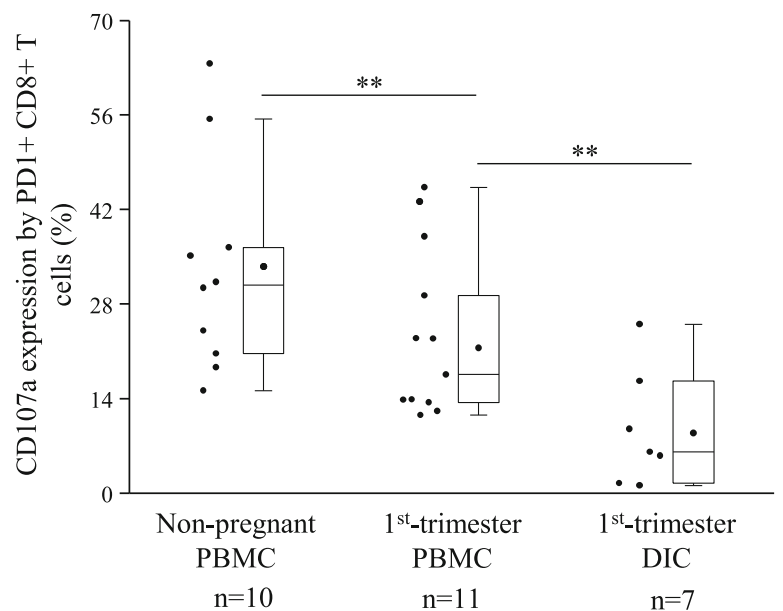

B

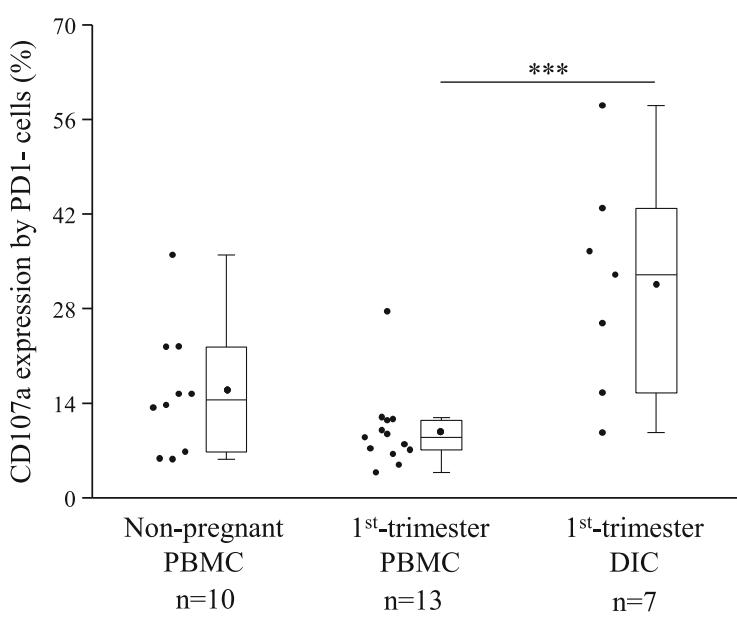

D

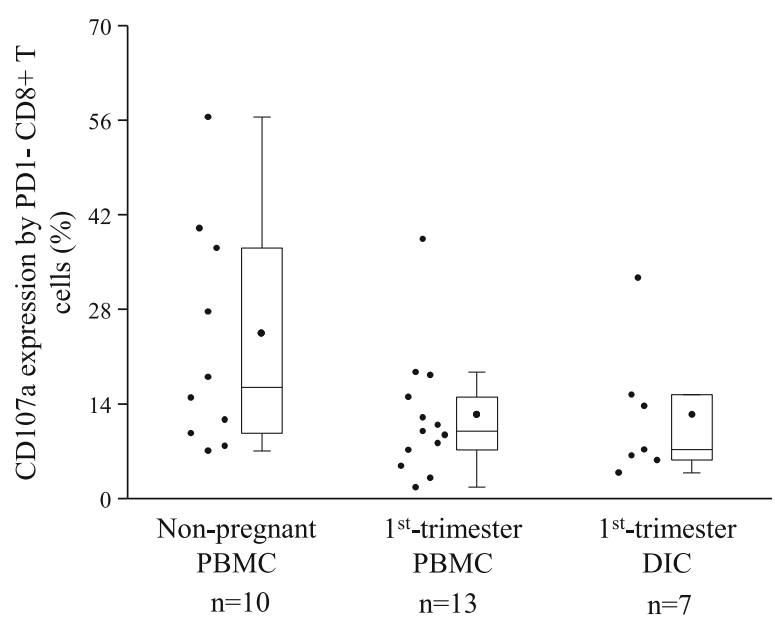

Fig. 4 Cytotoxicity of PD-1 positive/negative immune cell populations in 1st-trimester healthy pregnant and in non-pregnant women. Box plot of the median, the 25th and, 75th percentiles, range, and individual data values for the expression of the CD107a molecule by PD-1+/PD-1 negative immune cells ( $\mathbf{a}$ and $\mathbf{b}$ ) and PD-1+/PD-1 negative CD8+ T cells (c and $\mathbf{d}$ ) in peripheral blood and decidual tissue in healthy pregnant and in nonpregnant women. The middle line within the box represent medians of 10, 13 and 7 determinations, respectively, the middle dot within the box represents the mean, the boxes indicate the interquartile ranges and the whiskers show the most extreme observations. Differences were considered statistically significant for $p$-values $\leq 0.05 .{ }^{* *} p<0,01 ;{ }^{* *} p<0,03$

pregnancy, and we found and that the receptor expression by decidual CD8+ T, CD4+ T, and NKT-like cells was significantly increased compared to the periphery. Taglauer et al. further reported an elevated PD-1 expression by decidual CD8+ T and CD4+ T compared to the peripheral blood from the third trimester of pregnancy [44]. According to these results, it can be assumed that resident decidual CD8+ T cells express the PD-1 receptor on the surface in a high level during pregnancy ensuring a possible regulation in order to avoid exaggerated inflammatory effects.

The presence of immune-checkpoint ligands on the surface of trophoblast cells was already reported [46].
High PD-L1 expression by syncytiotrophoblast in early and term healthy pregnancy was also published [47] which confirms the importance of this regulatory pathway during pregnancy although there are few data about the presence of PD-L1 ligand on the surface of decidual immune cells. $\mathrm{Li}$ et al. presenting information about the expression of PD-L1 by Treg cells but only in mRNA level [43]. Another publication revealed that decidual monocytes express PD-L1 in the first trimester of pregnancy [45]. Our study is the first to investigate the expression level of PD-L1 molecule by different decidual immune cells. According to our analyses, we found a significantly increased PD-L1 expression by CD4+ T, 


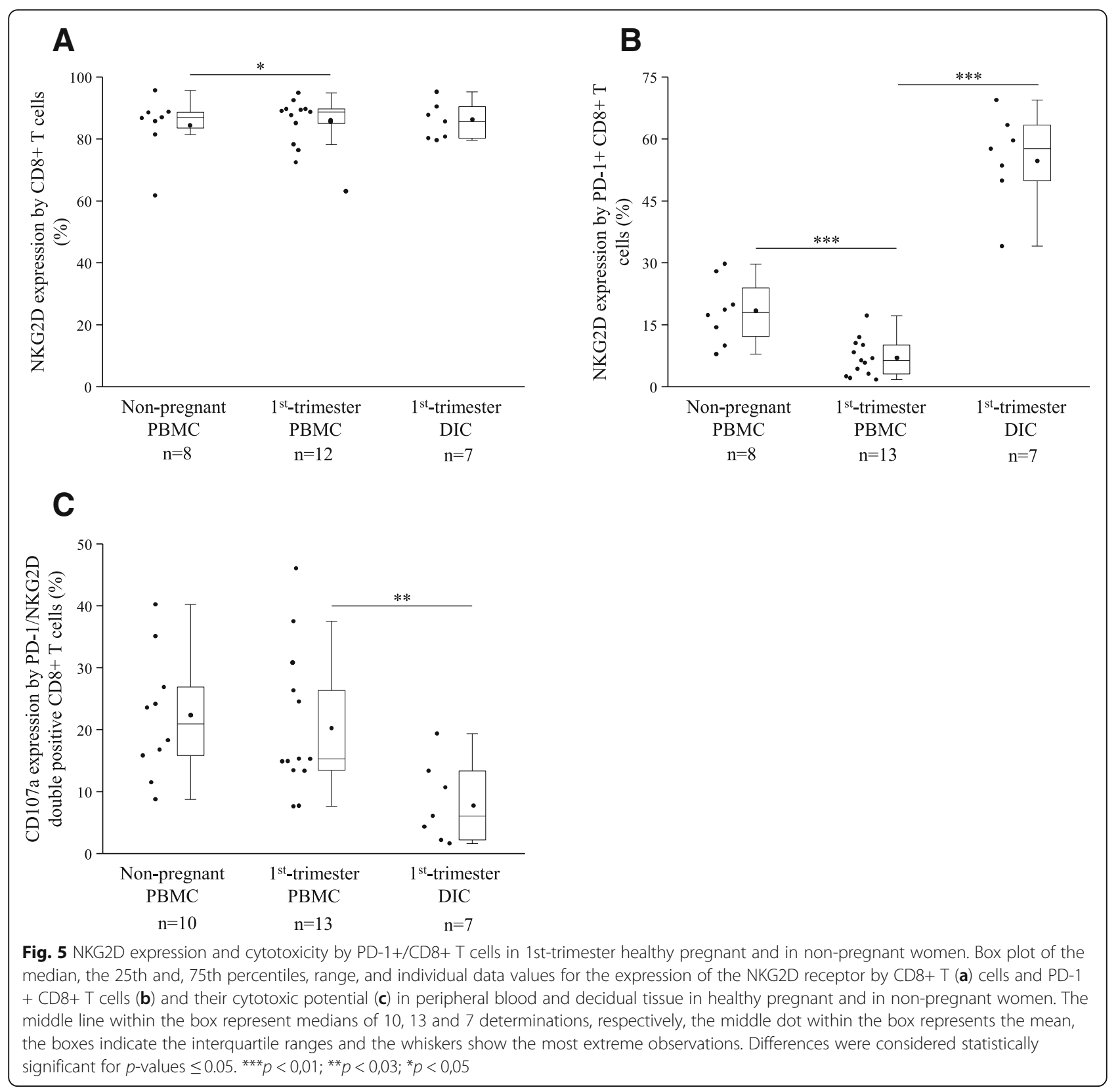

Treg, CD56 + NK, CD56 ${ }^{\text {dim }}$ NK, and NKT-like cells. Besides the presence of PD-L1 in the surface of the syncytiotrophoblast and decidual monocytes, we think that the down-regulation of the accumulated PD- $1+\mathrm{CD} 8+\mathrm{T}$ cells in the decidua may occur by the PD-L1 molecule expressed by the Tregs or by CD $56+$ NK cells locally, which is the most abundant decidual immune subpopulation at the MFI.

After phenotypic analyses, the CD107a degranulation assay was performed to collect further information about the importance of the PD-1/PD-L1 pathway during a healthy pregnancy. Our result showed that CD107a expression by the decidual PD-1 negative immune cells was elevated compared to the periphery, while a significant difference was not observed by the PD-1+ subpopulations. We also investigated the cytotoxic potential of CD8+ T cells depending on the presence of the PD-1 receptor on their surface. We measured a significantly decreased cytotoxic activity by decidual PD-1+ CD8+ T cells compared to the peripheral counterparts. However, we did not find any significant differences in the case of PD-1 negative CD8+ T cells. These data support our theory that PD-1/PD-L1 interaction influences the effector mechanisms of inflammatory immune responses at the MFI already in the first trimester.

An activatory molecule NKG2D was further involved in this study, which is a key receptor on all CD56 + NK 
cells, including uterine CD56 + NK cells [48] and it is also expressed by $\mathrm{CD} 8+\mathrm{T}$ cells in a high level. In humans, two families of NKG2D ligands have been discovered, namely MICA, MICB and ULBP1-6 [49]. Liu et al. detected the expression of NKG2D by decidual CD56 + NK cells and ULBP-1 molecule in the surface of syncytiotrophoblast cells [33]. This paper further revealed a relationship between abnormal expression pattern of ULBP-1 by syncytiotrophoblast cells and insufficient invasion ability, which may lead to early-onset preeclampsia [33]. Our study focused on the CD8 $+\mathrm{T}$ cell population and their NKG2D expression, which was significantly elevated in the first trimester of pregnancy compared to non-pregnant controls. Recent studies showed that NKG2D ligands could shed from the surface of cancer cells and mediate immunosuppressive function, which causes the lack of immune surveillance against tumor cells $[50,51]$. Another paper emphasizes that soluble NKG2D ligands may interfere and could limit the efficacy of immune-checkpoint blockers therapy [52]. It seems that soluble or surface form of NKG2D ligands have a different effect on the receptor-expressing cells. Therefore, we analyzed the co-expression of NKG2D and PD-1 receptors on the surface of CD8+ T cells. The decreased NKG2D expression by PD- $1+\mathrm{CD} 8+\mathrm{T}$ cells in the first trimester of pregnancy compared to non-pregnant control accompanied by the elevated NKG2D expression by the decidual PD-1+ CD8+ T cells compared to the periphery may indicate the accumulation of PD-1+ NKG2D ${ }^{\text {high }} \mathrm{CD} 8+\mathrm{T}$ cells at the MFI. Soluble NKG2D ligands from the trophoblast could possibly interact with NKG2D receptors expressed at a high level by local PD-1+CD8+ T cells. This interaction could play a role in the regulation of these effector cells by reducing their cytotoxic activity via decreased CD107a expression. However, PD-1+ NKG2D ${ }^{\text {high }}$ CD8+ T cell interaction via surface NKG2D ligands by the trophoblast could support the invasion of extravillous trophoblast and/or attend in the protection against microbial infections.

There were some limitations to the present study. Firstly, due to technical difficulties, we were not able to separate appropriate amount of cells from decidual tissues to perform all experiments on all samples. Second, functional assays of the investigated cells should be performed in the future to investigate the relationship between PD-1 positive immune cells and PD-L1 molecules.

\section{Conclusion}

The results of this present study demonstrate the complexity of the activating and inhibitory mechanisms at the MFI. Our findings suggest that PD-1/PD-L1 immune-checkpoint pathway could play a novel role in the maintenance of this sensitive immunological balance between the mother and the fetus.

\section{Abbreviations}

DIC: Decidual immune cells; NK: Natural killer cells; PBMC: Peripheral blood mononuclear cells; PD-1: Programmed cell death protein 1; PD-L1: Programmed cell death ligand-1

\section{Acknowledgments}

We would like to thank all the women who participated in the study.

\section{Funding}

This work was supported by grants from the National Research, Development and Innovation Office (NKFIH K1 19529), grants from the University of Pecs (KA-2018-07 and KA-2018-18), and the Development of scientific workshops of medical, health sciences and pharmaceutical educations (EFOP-3.6.3-VEKOP-16-2017-00009). All providers of support had no role in the design, data collection and analysis, decision to publish, or preparation of the manuscript.

\section{Availability of data and materials}

The data used to support the findings of this study are available from the corresponding author upon request.

\section{Authors' contributions}

Conceptualized the paper: MM, LSZ. Performed experiments: MM, BSZ. Analyzed the data and presented in the paper: MM. Statistical analyses: NF, MM. Wrote the paper: MM, EM, LSZ. Final review of the manuscript and approved the final version for submission: all the authors.

\section{Ethics approval and consent to participate}

The collection of the samples and experimental procedures were approved by the Regional Ethics Committee at the Medical School, University of Pécs (approved protocol registration number: 6149) and written informed consent was obtained from all participant. The study protocol conforms to the ethical guidelines of the 1975 Declaration of Helsinki.

\section{Consent for publication}

Not applicable.

\section{Competing interests}

The authors declare that they have no competing interests.

\section{Publisher's Note}

Springer Nature remains neutral with regard to jurisdictional claims in published maps and institutional affiliations.

\section{Author details}

'Department of Medical Microbiology and Immunology, University of Pecs, Medical School, 7624 Pecs, 12 Szigeti Street, Pecs, Hungary. ${ }^{2}$ Janos Szentagothai Research Centre, 7624 Pecs, 20 Ifjusag Street, Pecs, Hungary. ${ }^{3}$ Institute of Bioanalysis, University of Pecs, Medical School, 7624 Pecs, 12 Szigeti Street, Pecs, Hungary.

Received: 28 November 2018 Accepted: 7 February 2019

Published online: 19 February 2019

\section{References}

1. Sykes L, Maclntyre DA, Yap XJ, Teoh TG, Bennett PR. The Th1:th2 dichotomy of pregnancy and preterm labour. Mediat Inflamm. 2012;2012:967629. https://doi.org/10.1155/2012/967629.

2. Lin H, Mosmann TR, Guilbert L, Tuntipopipat S, Wegmann TG. Synthesis of T helper 2-type cytokines at the maternal-fetal interface. J Immunol. 1993;151: 4562-73 http://www.ncbi.nlm.nih.gov/pubmed/8409418. Accessed 12 Mar 2013.

3. Borzychowski AM, Croy BA, Chan WL, Redman CWG, Sargent IL. Changes in systemic type 1 and type 2 immunity in normal pregnancy and pre-eclampsia may be mediated by natural killer cells. Eur J Immunol. 2005;35:3054-63. https://doi.org/10.1002/eji.200425929.

4. Freeman GJ, Long AJ, Iwai Y, Bourque K, Chernova T, Nishimura H, et al. Engagement of the PD-1 immunoinhibitory receptor by a novel B7 family member leads to negative regulation of lymphocyte activation. J Exp Med. 2000;192:1027-34 http://www.pubmedcentral.nih.gov/articlerender. fcai?artid=2193311\&tool=pmcentrez\&rendertype=abstract. Accessed 3 Jun 2014 
5. Francisco LM, Sage PT, Sharpe AH. The PD-1 pathway in tolerance and autoimmunity. Immunol Rev. 2010;236:219-42. https://doi.org/10.1111/ j.1600-065X.2010.00923.x

6. Keir ME, Butte MJ, Freeman GJ, Sharpe AH. PD-1 and its ligands in tolerance and immunity. Annu Rev Immunol. 2008;26:677-704. https://doi.org/ 10.1146/annurev.immunol.26.021607.090331

7. Agata $Y$, Kawasaki A, Nishimura $H$, Ishida $Y$, Tsubata $T$, Yagita $H$, et al. Expression of the PD-1 antigen on the surface of stimulated mouse $\mathrm{T}$ and $\mathrm{B}$ lymphocytes. Int Immunol. 1996;8:765-72 http://www.ncbi.nlm.nih.gov/ pubmed/8671665. Accessed 26 Jan 2018.

8. Barber DL, Wherry EJ, Masopust D, Zhu B, Allison JP, Sharpe AH, et al. Restoring function in exhausted CD8 T cells during chronic viral infection. Nature. 2006;439:682-7. https://doi.org/10.1038/nature04444.

9. Qiu M-K, Wang S-C, Dai Y-X, Wang S-Q, Ou J-M, Quan Z-W. PD-1 and Tim-3 pathways regulate CD8+ T cells function in atherosclerosis. PLoS One. 2015;10:e0128523. https://doi.org/10.1371/journal.pone.0128523.

10. Yamazaki T, Akiba H, Iwai H, Matsuda H, Aoki M, Tanno $Y$, et al. Expression of programmed death 1 ligands by murine T cells and APC. J Immunol. 2002;169:5538-45 http://www.ncbi.nlm.nih.gov/pubmed/12421930. Accessed 26 Jan 2018.

11. Ishida M, Iwai Y, Tanaka Y, Okazaki T, Freeman GJ, Minato N, et al. Differential expression of PD-L1 and PD-L2, ligands for an inhibitory receptor PD-1, in the cells of lymphohematopoietic tissues. Immunol Lett. 2002;84:57-62 http://www.ncbi.nlm.nih.gov/pubmed/12161284. Accessed 26 Jan 2018.

12. Keir ME, Liang SC, Guleria I, Latchman YE, Qipo A, Albacker LA, et al. Tissue expression of PD-L1 mediates peripheral T cell tolerance. J Exp Med. 2006;203:883-95. https://doi.org/10.1084/jem.20051776.

13. Nagamatsu T, Schust DJ, Sugimoto J, Barrier BF. Human decidual stromal cells suppress cytokine secretion by allogenic CD4+ T cells via PD-1 ligand interactions. Hum Reprod. 2009;24:3160-71. https://doi.org/10.1093/ humrep/dep308.

14. Ansari MJl, Salama AD, Chitnis T, Smith RN, Yagita H, Akiba H, et al. The programmed death-1 (PD-1) pathway regulates autoimmune diabetes in nonobese diabetic (NOD) mice. J Exp Med. 2003;198:63-9. https://doi.org/ 10.1084/jem.20022125

15. Iwai Y, Terawaki S, Ikegawa M, Okazaki T, Honjo T. PD-1 inhibits antiviral immunity at the effector phase in the liver. J Exp Med. 2003;198:39-50. https://doi.org/10.1084/jem.20022235.

16. Panjwani PK, Charu V, DeLisser M, Molina-Kirsch H, Natkunam Y, Zhao S. Programmed death-1 ligands PD-L1 and PD-L2 show distinctive and restricted patterns of expression in lymphoma subtypes. Hum Pathol. 2018;71:91-9. https://doi.org/10.1016/j.humpath.2017.10.029.

17. Mishra AK, Kadoishi T, Wang X, Driver E, Chen Z, Wang X-J, et al. Squamous cell carcinomas escape immune surveillance via inducing chronic activation and exhaustion of CD8+ T cells co-expressing PD-1 and LAG-3 inhibitory receptors. Oncotarget. 2016;7:81341-56. https://doi.org/10.18632/ oncotarget.13228.

18. Fife BT, Pauken KE. The role of the PD-1 pathway in autoimmunity and peripheral tolerance. Ann N Y Acad Sci. 2011;1217:45-59. https://doi.org/ 10.1111/j.1749-6632.2010.05919.x.

19. Thangavelu G, Parkman JC, Ewen CL, Uwiera RRE, Baldwin TA, Anderson CC. Programmed death-1 is required for systemic self-tolerance in newly generated T cells during the establishment of immune homeostasis. J Autoimmun. 2011;36:301-12. https://doi.org/10.1016/j.jaut.2011.02.009.

20. Blackburn SD, Shin H, Haining WN, Zou T, Workman CJ, Polley A, et al. Coregulation of CD8+ T cell exhaustion by multiple inhibitory receptors during chronic viral infection. Nat Immunol. 2009;10:29-37. https://doi.org/ 10.1038/ni.1679

21. Wang S-C, Li Y-H, Piao H-L, Hong X-W, Zhang D, Xu Y-Y, et al. PD-1 and Tim-3 pathways are associated with regulatory CD8+ T-cell function in decidua and maintenance of normal pregnancy. Cell Death Dis. 2015;6:e1738. https://doi.org/10.1038/cddis.2015.112.

22. Bai J, Gao Z, Li X, Dong L, Han W, Nie J. Regulation of PD-1/PD-L1 pathway and resistance to PD-1/PD-L1 blockade. Oncotarget. 2017:8:110693-707. https://doi.org/10.18632/oncotarget.22690.

23. Riella LV, Paterson AM, Sharpe AH, Chandraker A. Role of the PD-1 pathway in the immune response. Am J Transplant. 2012;12:2575-87. https://doi.org/ 10.1111/j.1600-6143.2012.04224.x.

24. Singh B, Salama A. Updates in therapy for advanced melanoma. Cancers (Basel). 2016:8:17. https://doi.org/10.3390/cancers8010017.
25. Gupta K, Tiu DY, Tiu J, Aragon-Ching JB. The promising role of nivolumab in renal cell cancers. Cancer Biol Ther. 2016;17:123-4. https://doi.org/10.1080/ 15384047.2016.1139269.

26. Rosati LM, Kumar R, Herman JM. Integration of stereotactic body radiation therapy into the multidisciplinary Management of Pancreatic Cancer. Semin Radiat Oncol. 2017;27:256-67. https://doi.org/10.1016/j.semradonc.2017.02.005.

27. Wu S-P, Liao R-Q, Tu H-Y, Wang W-J, Dong Z-Y, Huang S-M, et al. Stromal PD-L1+regulatory T cells and PD-1+CD8+ T cells define the response of different subsets of non-small-cell lung cancer to PD-1/PD-L1 blockade immunotherapy. J Thorac Oncol. 2017. https://doi.org/10.1016/j.jtho.2017.11.132.

28. Tanaka K, Albin MJ, Yuan X, Yamaura K, Habicht A, Murayama T, et al. PDL1 is required for peripheral transplantation tolerance and protection from chronic allograft rejection. J Immunol. 2007;179:5204-10 http://www.ncbi. nlm.nih.gov/pubmed/17911605. Accessed 1 Feb 2018.

29. Wang W, Carper K, Malone F, Latchman Y, Perkins J, Fu Y, et al. PD-L1/PD-1 signal deficiency promotes allogeneic immune responses and accelerates heart allograft rejection. Transplantation. 2008:86:836-44. https://doi.org/10. 1097/TP.0b013e3181861932.

30. Koehn BH, Ford ML, Ferrer IR, Borom K, Gangappa S, Kirk AD, et al. PD-1dependent mechanisms maintain peripheral tolerance of donor-reactive CD8+ T cells to transplanted tissue. J Immunol. 2008;181:5313-22 http:// www.ncbi.nlm.nih.gov/pubmed/18832687. Accessed 1 Feb 2018.

31. Maasho K, Opoku-Anane J, Marusina Al, Coligan JE, Borrego F. NKG2D is a costimulatory receptor for human naive CD8+ T cells. J Immunol 2005;174 4480-4484. http://www.ncbi.nlm.nih.gov/pubmed/15814668. Accessed 28 Jan 2019.

32. Cosman D, Müllberg J, Sutherland CL, Chin W, Armitage R, Fanslow W, et al. ULBPs, novel MHC class I-related molecules, bind to CMV glycoprotein UL16 and stimulate NK cytotoxicity through the NKG2D receptor. Immunity. 2001;14:123-33 http://www.ncbi.nlm.nih.gov/pubmed/11239445. Accessed 21 Feb 2018.

33. Liu J, Song G, Lin X, Pang X, Meng T. Upregulated unique long 16 binding protein 1 detected in preeclamptic placenta affects human extravillous trophoblast cell line (HTR-8/SVneo) invasion by modulating the function of uterine natural killer cells. Exp Ther Med. 2017;13:1447-55. https://doi.org/ 10.3892/etm.2017.4143.

34. Zou W, Wolchok JD, Chen L. PD-L1 (B7-H1) and PD-1 pathway blockade for cancer therapy: mechanisms, response biomarkers, and combinations. Sci Transl Med 2016;8:328rv4-328rv4. https://doi.org/10.1126/scitranslmed.aad7118.

35. Brahmer JR, Tykodi SS, Chow LQM, Hwu W-J, Topalian SL, Hwu P, et al. Safety and activity of anti-PD-L1 antibody in patients with advanced Cancer. N Engl J Med. 2012;366:2455-65. https://doi.org/10.1056/ NEJMoa1200694.

36. Shen MJ, Xu LJ, Yang L, Tsai Y, Keng PC, Chen Y, et al. Radiation alters PD-L1/NKG2D ligand levels in lung cancer cells and leads to immune escape from NK cell cytotoxicity via IL-6-MEK/Erk signaling pathway. Oncotarget. 2017;8:80506-20. https://doi.org/10.18632/oncotarget.19193.

37. Sandner SE, Clarkson MR, Salama AD, Sanchez-Fueyo A, Domenig C, Habicht $A$, et al. Role of the programmed death-1 pathway in regulation of alloimmune responses in vivo. J Immunol. 2005;174:3408-15 http://www. ncbi.n/m.nih.gov/pubmed/15749874. Accessed 1 Feb 2018

38. Habicht A, Dada S, Jurewicz M, Fife BT, Yagita H, Azuma M, et al. A link between PDL1 and T regulatory cells in fetomaternal tolerance. J Immunol. 2007;179:5211-9 http://www.ncbi.nlm.nih.gov/pubmed/17911606. Accessed 1 Feb 2018.

39. Laganà AS, Vitale SG, Sapia F, Valenti G, Corrado F, Padula F, et al. miRNA expression for early diagnosis of preeclampsia onset: hope or hype? J Matern Fetal Neonatal Med. 2018;31:817-21. https://doi.org/10.1080/ 14767058.2017.1296426.

40. Laganà AS, Favilli A, Triolo O, Granese R, Gerli S. Early serum markers of pre-eclampsia: are we stepping forward? J Matern Fetal Neonatal Med. 2016;29:3019-23. https://doi.org/10.3109/14767058.2015.1113522.

41. Laganà AS, Giordano D, Loddo S, Zoccali G, Vitale SG, Santamaria A, et al. Decreased endothelial progenitor cells (EPCS) and increased natural killer (NK) cells in peripheral blood as possible early markers of preeclampsia: a case-control analysis. Arch Gynecol Obstet. 2017;295:867-72. https://doi.org/ 10.1007/s00404-017-4296-x.

42. Szereday L, Miko E, Meggyes M, Barakonyi A, Farkas B, Varnagy A, et al. Commitment of decidual haematopoietic progenitor cells in first trimester pregnancy. Am J Reprod Immunol. 2012;67:9-16. https://doi.org/10.1111/ j.1600-0897.2011.01029.x 
43. Li G, Lu C, Gao J, Wang X, Wu H, Lee C, et al. Association between PD-1/PD-L1 and T regulate cells in early recurrent miscarriage. Int J Clin Exp Pathol. 2015;8:6512-8 http://www.ncbi.nlm.nih.gov/pubmed/26261529. Accessed 20 Feb 2018.

44. Taglauer ES, Trikhacheva AS, Slusser JG, Petroff MG. Expression and function of PDCD1 at the human maternal-fetal interface. Biol Reprod. 2008;79:562-9. https://doi.org/10.1095/biolreprod.107.066324.

45. Sayama S, Nagamatsu T, Schust DJ, Itaoka N, Ichikawa M, Kawana K, et al. Human decidual macrophages suppress IFN- $\gamma$ production by $T$ cells through costimulatory B7-H1:PD-1 signaling in early pregnancy. J Reprod Immunol. 2013;100:109-17. https://doi.org/10.1016/j.jri.2013.08.001.

46. Enninga EAL, Harrington SM, Creedon DJ, Ruano R, Markovic SN, Dong $H$, et al. Immune checkpoint molecules soluble program death ligand 1 and galectin-9 are increased in pregnancy. Am J Reprod Immunol. 2018;79:e12795. https://doi.org/10.1111/aji.12795.

47. Veras E, Kurman RJ, Wang T-L, Shih I-M. PD-L1 expression in human placentas and gestational trophoblastic diseases. Int J Gynecol Pathol. 2017; 36:146-53. https://doi.org/10.1097/PGP.0000000000000305.

48. Hanna J, Goldman-Wohl D, Hamani Y, Avraham I, Greenfield C, Natanson-Yaron S, et al. Decidual NK cells regulate key developmental processes at the human fetal-maternal interface. Nat Med. 2006;12:1065-74. https://doi.org/10.1038/nm1452.

49. Spear $P$, Wu M-R, Sentman $M-L$, Sentman $C L$. NKG2D ligands as therapeutic targets. Cancer Immun 2013;13:8. http://www.ncbi.nlm.nih.gov/pubmed/ 23833565. Accessed 21 Feb 2018.

50. Zocchi MR, Camodeca C, Nuti E, Rossello A, Venè R, Tosetti F, et al. ADAM10 new selective inhibitors reduce NKG2D ligand release sensitizing Hodgkin lymphoma cells to NKG2D-mediated killing. Oncoimmunology. 2016;5:e1123367. https://doi.org/10.1080/2162402X.2015.1123367.

51. López-Soto A, Gonzalez S, Smyth MJ, Galluzzi L. Control of metastasis by NK cells. Cancer Cell. 2017;32:135-54. https://doi.org/10.1016/j.ccell.2017.06.009.

52. López-Soto A, Gonzalez S, Galluzzi L. Soluble NKG2D ligands limit the efficacy of immune checkpoint blockade. Oncoimmunology. 2017;6:e1346766. https://doi.org/10.1080/2162402X.2017.1346766.

Ready to submit your research? Choose BMC and benefit from:

- fast, convenient online submission

- thorough peer review by experienced researchers in your field

- rapid publication on acceptance

- support for research data, including large and complex data types

- gold Open Access which fosters wider collaboration and increased citations

- maximum visibility for your research: over $100 \mathrm{M}$ website views per year

At $\mathrm{BMC}$, research is always in progress.

Learn more biomedcentral.com/submissions 